\title{
Review Article \\ Chlamydial Infection and Its Role in Male Infertility
}

\author{
Mary K. Samplaski, ${ }^{1}$ Trustin Domes, ${ }^{2}$ and Keith A. Jarvi' ${ }^{1,3,4}$ \\ ${ }^{1}$ Division of Urology, Department of Surgery, Mount Sinai Hospital, University of Toronto, 60 Murray Street, \\ 6th Floor, Toronto, ON, Canada M5T $3 L 9$ \\ ${ }^{2}$ Division of Urology, Department of Surgery, University of Saskatchewan, 105 Administration Place, Saskatoon, SK, Canada S7N 5A1 \\ ${ }^{3}$ Faculty of Medicine, Institute of Medical Science, University of Toronto, Toronto, ON, Canada M5T 3L9 \\ ${ }^{4}$ Lunenfeld Tanenbaum Research Institute, Mount Sinai Hospital, Toronto, ON, Canada M5T 3L9 \\ Correspondence should be addressed to Keith A. Jarvi; KJarvi@mtsinai.on.ca
}

Received 20 November 2013; Revised 28 February 2014; Accepted 30 April 2014; Published 1 June 2014

Academic Editor: Mónica Hebe Vazquez-Levin

Copyright (C) 2014 Mary K. Samplaski et al. This is an open access article distributed under the Creative Commons Attribution License, which permits unrestricted use, distribution, and reproduction in any medium, provided the original work is properly cited.

Introduction. Chlamydia trachomatis is an established cause of tubal factor infertility; however its role in male fertility is not as clear. We sought to determine the prevalence of Chlamydia in infertile men and evaluate its impact on male reproductive potential. Materials and Methods. We compared the incidence of Chlamydia in our infertile male population with that reported in the literature. We then reviewed the impact of Chlamydia infection on male fertility. Results. The incidence of Chlamydia infection in our population of infertile men was $0.3 \%$. There is considerable variability in the reported incidence, likely due to variation in the population studied, and detection technique. The optimal testing method and sample are presently unclear. The effect of Chlamydia on male reproductive function is also variable in the literature, but appears to be relatively minimal and may be related primarily to sperm DNA fragmentation or female partner transmission. Conclusions. The prevalence of Chlamydia in the infertile male population is low and routine testing is not supported by the literature. For high-risk infertile men, nucleic acid testing of urine $+/$ - semen is the most sensitive method to detect Chlamydia. A validated testing system for semen needs to be developed, so that a standardized methodology can be recommended. In this way the full implications of Chlamydia on male fertility can be elucidated.

\section{Introduction}

Chlamydia trachomatis (C. trachomatis) is the most prevalent sexually transmitted disease in the world and a common cause of pathology in both men and women, causing urethritis, epididymitis, prostatitis, cervicitis, pelvic inflammatory disease (PID), ectopic pregnancy, and tubal factor infertility [1]. While there are regional differences in the prevalence, it remains a common cause of genitourinary pathology in both men and women. In women $C$. trachomatis is a wellestablished cause of tubal factor infertility. In men it is a known common genitourinary pathogen, and electron microscopy has clearly demonstrated that $C$. trachomatis attach to spermatozoa [2-5], both on the surface and in the nucleus [6]; however its role in male fertility (sperm function, pregnancy rates, and live birth rates) is not clear.
As the etiology of approximately $55 \%$ of male factor infertility is unknown, it is possible that Chlamydia is contributory in some of these cases. In our study in a Canadian clinic, we identified a very low prevalence of Chlamydia in the infertile male population of only $0.3 \%$ [7]. This is the largest study of the prevalence of $C$. trachomatis ever published on infertile men with a total of 5588 men studied, and certainly seems to indicate that $C$. trachomatis infections are highly uncommon in men with infertility. However, there are significant differences in the reported prevalence of $C$. trachomatis infections in men with infertility, which vary by region and C. trachomatis detection techniques. In light of these findings, we sought to determine the overall prevalence of $C$. trachomatis in infertile men, and if the reported prevalence rates might be affected by the technique of $C$. trachomatis 
detection or reflect a real difference in regional C. trachomatis rates.

\section{Prevalence}

C. trachomatis is the most prevalent sexually transmitted disease in the world [8]. Among infertile males, there is considerable variability in the rate of $C$. trachomatis infection, ranging from 0 to $90.3 \%$ (Table 1 ) [2, 3, 6, 9-39]. In our population of infertile Canadian males, we determined the prevalence of Chlamydia infection to be on the lower end of this spectrum, $0.304 \%$ [7]. Notably, in our population there was a reported history of treated Chlamydia of $2 \%$, which still suggests a low prevalence in the infertile male population. The reported variability in Chlamydia prevalence is likely derived in part from the population studied, screening method, and type of sample used [2]. From 2007 to 2008, C. trachomatis prevalence in the United States among 14-39 year olds was $1.6 \%$, with higher rates seen among females (2.2\% versus $1.1 \%$ in males), African Americans (6.7\%), and adolescents aged from 14 to 19 years $(2.5 \%)$ [40]. This was slightly different than what we observed in our population, where the mean age of men that tested positive for Chlamydia was 35 years; however this represents a skewed population of men, who are presenting for fertility evaluation. In addition, there does seem to be some geographic variability in C. trachomatis prevalence. Rates are low in individuals throughout northern Europe, Iran, and Japan (mean of $2.7 \%$ ) but higher in Tunisia (43\%), South Africa (34\%), and India (33\%) [21, 41]. In addition, it is believed that the actual prevalence of Chlamydia is underestimated, in part, due to its (at times) asymptomatic nature [42].

\section{Biology}

C. trachomatis is intracellular bacteria that produces a wide variety of clinical pathologies. The organism has a unique developmental cycle in which it exists in two forms: the inactive elementary body and the infectious reticulate body, providing a mechanism for continued transmission among sexual partners. Elementary bodies, reticulate bodies, or the lipopolysaccharide that they release, may be encountered by any gametes that are present in the reproductive tract at that time. The full clinical consequences of exposure are still being uncovered but are likely multifaceted.

Infection is characterized by a range of clinical manifestations, from a subclinical infection to a robust inflammatory response [1]. Up to $75 \%$ of cases in women and $50 \%$ in men are asymptomatic, which may lead to repeated transmission [9]. We found this to be true in our study of Canadian infertile men, where none of the men that tested positive for Chlamydia reported any symptoms of infection on history or physical exam [7]. The level of immune response to C. trachomatis may be affected by the size of the initial inoculum and the number of repeated infections, as well as genetic variation. Such genetic variation has been shown to correlate with $C$. trachomatis infection with the severity of tubal damage in women [43]. These responses have been studied primarily in women but likely can be extrapolated to men.

Chlamydia can persist in the host even after the development of an immune response, leading to chronic infection [1]. Surprisingly, only $15 \%$ of the men in our cohort who tested positive for Chlamydia reported a prior history of sexually transmitted disease [7], suggesting that most of these men cleared their initial infection. It is unclear why some individuals clear infections, while others do not; however some evidence has shown that the cytokine IFN- $\gamma$ may be involved [44]. Persistence is serologically characterized by elevated C. trachomatis heat shock protein 60 (CHSP60) [45], which in women has been associated with PID, ectopic pregnancy, scarring trachoma, tubal infertility, and spontaneous pregnancy loss $[45,46]$.

\section{Testing}

Some of the variability that we observed in the prevalence of Chlamydia infection is likely due to a variety of testing methods, which have variable sensitivities and specificities, and also different implications for fertility in both men and women.

Current screening recommendations for C. trachomatis in the infertile couple are vague, and at the present time it is not clear how to best detect $C$. trachomatis in the male. This was part of why in our initial study we tested both urine and semen samples [7]. Review of the male fertility literature reveals that in the past many different methods, as well as a variety of specimens, have been used (serum, urethral swab, urine, and semen). First catch urine has become the most widely accepted testing method for $C$. trachomatis detection [47]. Testing of semen for C. trachomatis is a relatively recent concept and currently there is no approved methodology for Chlamydia testing in semen [47-49]. Most commercially available methods have rarely been applied to the detection of C. trachomatis in semen [48], and in our study we used nucleic acid testing of both urine and semen in order to assess if there would be some cases which were captured by semen testing alone [7].

The role of seminal testing is not known. It is thought that the presence of Chlamydia in semen may indicate an infection of the upper genital tract $[20,34,37,50]$; however this may also reflect a contaminated urethra, through which the ejaculate passes. A recent review by Eley and Pacey [41] found that semen testing does uniquely capture some cases of Chlamydia infection, a finding which was corroborated by our study [7]. The presence of C. trachomatis in urethral samples and its absence in semen specimens may indicate an asymptomatic lower tract infection that may have less fertility-related relevance. However, patients testing positive for $C$. trachomatis DNA in semen specimens and negative for C. trachomatis DNA in urethral samples may indicate that $C$. trachomatis resides in the male secretory glands and as such may serve as a marker for an invasive Chlamydial infection [51]. 
TABle 1: Frequency of C. trachomatis detection among infertile males.

\begin{tabular}{|c|c|c|c|c|}
\hline Author & Year & Method of C. trachomatis testing & Specimen tested & $\begin{array}{c}\text { Men testing positive } \\
\text { for Chlamydia }\end{array}$ \\
\hline Nagy et al. [10] & 1989 & Culture & Semen & $14.1 \%(26 / 184)$ \\
\hline Bjercke and Purvis [14] & 1992 & ELISA for Chlamydia IgA & Semen & $24 \%(24 / 100)$ \\
\hline \multirow{2}{*}{ Eggert-Kruse et al. [15] } & \multirow{2}{*}{1992} & ELISA for Chlamydia IgG & Serum & 0 \\
\hline & & Culture & Urethral swab & 0 \\
\hline \multirow{5}{*}{ Samra et al. [16] } & \multirow{5}{*}{1994} & Culture & Urethral swab & $9.6 \%(13 / 135)$ \\
\hline & & ELISA for Chlamydia IgG & Serum & $4.4 \%(6 / 135)$ \\
\hline & & ELISA for Chlamydia IgA & Serum & $1.5 \%(2 / 135)$ \\
\hline & & ELISA for Chlamydia IgG & Semen & 0 \\
\hline & & ELISA for Chlamydia IgA & Semen & $8.9 \%(12 / 135)$ \\
\hline \multirow{4}{*}{ Munoz and Witkin [12] } & \multirow{4}{*}{1995} & ELISA for Chlamydia IgG & Serum & $25 \%(12 / 48)$ \\
\hline & & ELISA for Chlamydia IgA & Serum & $16.7 \%(8 / 48)$ \\
\hline & & ELISA for Chlamydia IgG & Semen & $8.3 \%(4 / 48)$ \\
\hline & & ELISA for Chlamydia IgA & Semen & $29.1 \%(14 / 48)$ \\
\hline \multirow{5}{*}{ Dieterle et al. [17] } & \multirow{5}{*}{1995} & PCR & Semen & $8 \%(4 / 50)$ \\
\hline & & ELISA for Chlamydia IgG & Serum & $46 \%(23 / 50)$ \\
\hline & & ELISA for Chlamydia IgA & Serum & $12 \%(6 / 50)$ \\
\hline & & ELISA for Chlamydia IgG & Semen & $12 \%(6 / 50)$ \\
\hline & & ELISA for Chlamydia IgA & Semen & $16 \%(8 / 50)$ \\
\hline \multirow{4}{*}{ Eggert-Kruse et al. [18] } & \multirow{4}{*}{1996} & Immunofluorescence testing & Semen & 0 \\
\hline & & ELISA for Chlamydia IgG & Semen & $8.1 \%(16 / 197)$ \\
\hline & & ELISA for Chlamydia IgA & Semen & $18.8 \%(37 / 197)$ \\
\hline & & ELISA for Chlamydia IgG and IgA & Serum & $16.2 \%(32 / 197)$ \\
\hline Cengiz et al. [19] & 1997 & Monoclonal antibodies to Chlamydia & Urethral swab & $12.6 \%(36 / 284)$ \\
\hline \multirow{4}{*}{ Eggert-Kruse et al. [20] } & \multirow{4}{*}{1997} & Indirect immunofluorescence assay & Serum & $12.6 \%(164 / 1303)$ \\
\hline & & Tissue culture & Urethral swab & 0 \\
\hline & & ELISA for Chlamydia IgG & Semen & $1.5 \%(50 / 1303)$ \\
\hline & & ELISA for Chlamydia IgA & Semen & $3.5 \%(46 / 1303)$ \\
\hline \multirow{5}{*}{ Bornman et al. [21] } & \multirow{5}{*}{1998} & Tissue culture & Urethral swab & $18.3 \%(24 / 131)$ \\
\hline & & EIA & Urethral swab & $25.2 \%(33 / 131)$ \\
\hline & & DFA & Urethral swab & $26 \%(34 / 131)$ \\
\hline & & EIA & First void urine & $25.2 \%(33 / 131)$ \\
\hline & & EIA & Semen & $26.7 \%(35 / 131)$ \\
\hline \multirow{3}{*}{ Levy et al. [22] } & \multirow{3}{*}{1999} & ELISA for Chlamydia IgG & Serum & $22.8 \%(21 / 92)$ \\
\hline & & ELISA for Chlamydia IgA & Serum & $8.6 \%(8 / 92)$ \\
\hline & & PCR & Semen & $10.9 \%(10 / 92)$ \\
\hline \multirow{6}{*}{ Ochsendorf et al. [23] } & \multirow{6}{*}{1999} & ELISA for Chlamydia IgG and IgA & First void urine & $0.8 \%(1 / 125)$ \\
\hline & & ELISA for Chlamydia IgG and IgA & Ejaculate & 0 \\
\hline & & ELISA for Chlamydia IgG and IgA & Seminal plasma & $11.2 \%(14 / 125)$ \\
\hline & & ELISA for Chlamydia IgG and IgA & Serum & $31.2 \%(39 / 125)$ \\
\hline & & PCR & First void urine & $1.6 \%(2 / 125)$ \\
\hline & & PCR & Ejaculate & $1.6 \%(2 / 125)$ \\
\hline Habermann and Krause [24] & 1999 & ELISA for Chlamydia IgG and IgA & Semen & $90.3 \%(187 / 207)$ \\
\hline Videau et al. [25] & 2001 & ELISA for Chlamydia IgA & Semen & $23 \%(23 / 102)$ \\
\hline \multirow{4}{*}{ Mania-Pramanik et al. [26] } & \multirow{4}{*}{2001} & Direct antigen detection & Urine & $33.3 \%(5 / 15)$ \\
\hline & & Direct antigen detection & Semen & $13.3 \%(2 / 15)$ \\
\hline & & Direct antigen detection & Serum & 0 \\
\hline & & ELISA for Chlamydia IgG & Urine & 0 \\
\hline
\end{tabular}


TABLe 1: Continued.

\begin{tabular}{|c|c|c|c|c|}
\hline Author & Year & Method of C. trachomatis testing & Specimen tested & $\begin{array}{c}\text { Men testing positive } \\
\text { for Chlamydia }\end{array}$ \\
\hline & & & Semen & 0 \\
\hline & & & Serum & $46.7 \%(7 / 15)$ \\
\hline \multirow{4}{*}{ Bollmann et al. [27] } & \multirow{4}{*}{2001} & ELISA for Chlamydia IgA & Semen & $38.1 \%(317 / 834)$ \\
\hline & & ELISA for Chlamydia IgA & Serum & $19.1 \%(62 / 324)$ \\
\hline & & ELISA for Chlamydia IgG & Semen & $15.9 \%(133 / 834)$ \\
\hline & & ELISA for Chlamydia IgG & Serum & $67.9 \%(220 / 324)$ \\
\hline \multirow{7}{*}{ Gdoura et al. [28] } & \multirow{7}{*}{2001} & Direct fluorescence antibody & Semen & $1.1 \%(1 / 92)$ \\
\hline & & & Urethral swab & $4.3 \%(4 / 92)$ \\
\hline & & Cell culture & Urethral swab & $1.1 \%(1 / 92)$ \\
\hline & & PCR & Semen & $16.3 \%(15 / 92)$ \\
\hline & & PCR & Urethral swab & $18.5 \%(17 / 92)$ \\
\hline & & ELISA for Chlamydia IgA & Semen & $21.7 \%(20 / 92)$ \\
\hline & & ELISA for Chlamydia IgA & Urethral swab & $8.7 \%(8 / 92)$ \\
\hline Vigil et al. [6] & 2002 & Direct immunofluorescence & Semen or urethral swab & $38.6 \%(110 / 284)$ \\
\hline \multirow{2}{*}{ Eggert-Kruse et al. [29] } & \multirow{2}{*}{2003} & LCR & Urine & $1.6 \%(11 / 707)$ \\
\hline & & LCR & Semen & $0.7 \%(5 / 707)$ \\
\hline \multirow{2}{*}{ Idahl et al. [30] } & \multirow{2}{*}{2004} & Microimmunofluorescence for Chlamydia IgG & Serum & $20.1 \%(49 / 243)$ \\
\hline & & PCR & Urine & $7.1 \%(5 / 70)$ \\
\hline \multirow{5}{*}{ Hamdad-Daoudi et al. [31] } & \multirow{5}{*}{2004} & PCR & Urine & $3.6 \%(4 / 111)$ \\
\hline & & PCR & Prostatic massage & $0.9 \%(1 / 111)$ \\
\hline & & PCR & Semen & $2.7 \%(3 / 111)$ \\
\hline & & ELISA for Chlamydia IgG & Serum & $0.9 \%(1 / 111)$ \\
\hline & & ELISA for Chlamydia IgA & Serum & 0 \\
\hline \multirow{2}{*}{ Hosseinzadeh et al. [32] } & \multirow{2}{*}{2004} & PCR & Semen & $4.9 \%(31 / 642)$ \\
\hline & & LCR & Semen & $4.3 \%(28 / 642)$ \\
\hline \multirow{4}{*}{ de Barbeyrac et al. [33] } & \multirow{4}{*}{2006} & PCR & Semen & $0.3 \%(1 / 260)$ \\
\hline & & PCR & Urine & $0.7 \%(2 / 260)$ \\
\hline & & ELISA for Chlamydia IgG and IgA & Serum & $9.5 \%(22 / 231)$ \\
\hline & & ELISA for Chlamydia IgG and IgA & Semen & $4.3 \%(10 / 231)$ \\
\hline \multirow{2}{*}{ Gdoura et al. [34] } & \multirow{2}{*}{2008} & PCR & Semen & $42.3 \%(44 / 104)$ \\
\hline & & PCR & Urine & $39.4 \%(41 / 104)$ \\
\hline \multirow{2}{*}{ Joki-Korpela et al. [35] } & \multirow{2}{*}{2009} & EIA to Chlamydia IgG & Serum & $27.8 \%(25 / 90)$ \\
\hline & & EIA to Chlamydia IgA & Serum & $22.2 \%(20 / 90)$ \\
\hline \multirow{2}{*}{ Ouzounova-Raykova et al. [36] } & \multirow{2}{*}{2009} & Culture & Urethral swab & $6.6 \%(4 / 60)$ \\
\hline & & PCR & Urethral swab & $8.3 \%(5 / 60)$ \\
\hline \multirow{4}{*}{ Kokab et al. [37] } & \multirow{4}{*}{2010} & Strand displacement amplification & Urine & $3.5 \%(9 / 255)$ \\
\hline & & Strand displacement amplification & Semen & $7.0 \%(18 / 255)$ \\
\hline & & PCR & Urine & $2.4 \%(6 / 255)$ \\
\hline & & PCR & Semen & $6.3 \%(16 / 255)$ \\
\hline \multirow{3}{*}{ Eggert-Kruse et al. [38] } & \multirow{3}{*}{2011} & ELISA for Chlamydia IgG & Semen & $22.5 \%(39 / 173)$ \\
\hline & & ELISA for Chlamydia IgA & & $20.8 \%(36 / 173)$ \\
\hline & & ELISA for Chlamydia IgM & & $5.8 \%(10 / 173)$ \\
\hline Rybar et al. [39] & 2011 & Sperm chromatin structure assay & Semen & $13 \%(38 / 293)$ \\
\hline Domes et al. [7] & 2012 & Strand displacement amplification assay & Semen or urine & $0.3 \%(17 / 5588)$ \\
\hline
\end{tabular}


Unfortunately, there is no approved methodology for the testing of semen for C. trachomatis [49, 52]. In fact, the question as to whether semen is a suitable sample for detection of C. trachomatis in infertile men is not even completely clear [52], as components of seminal fluid have been shown to be toxic to cell culture growth [53]. Attempts to dilute semen to decrease the toxicity have resulted in a decreased sensitivity to detect C. trachomatis [50, 54]. Recommendations have been made for developing standardizing semen testing for $C$. trachomatis [41]; however at this point these have not led to a standardized protocol.

Historically, Chlamydia was grown in culture; however this was replaced in many centers by antigen detection [52]. This indirect approach is inherently flawed but nonetheless has been extensively utilized. The most commonly studied antibodies include those directed against $C$. trachomatis IgG and CHSP60. Most individuals with urogenital Chlamydial infection develop serum IgG and IgA antibodies, which persist for years and have been considered a marker of past infection [55]. Heat shock proteins are stress response proteins, and CHSP60 (a marker of Chlamydia persistence) stimulates the inflammatory response $[56,57]$. In male serum, $C$. trachomatis IgA and IgG, but not CHSP60 antibodies, have been shown to correlate with lower female partner pregnancy rates [58]. However, the role of $C$. trachomatis antibodies in men remains unclear.

The method that we used in our assessment of the incidence of Chlamydia infection in the infertile male population was nucleic acid amplification testing (NAAT) [7], which has become the method of choice for $C$. trachomatis detection [59]. NAAT has been shown to have better sensitivity than nonmolecular methods; however, an important consideration for using NAAT testing in semen is that there are more NAAT inhibitors in semen than in urine $[31,33]$. The presence of these inhibitors has been corroborated by the finding of a lowered sensitivity of NAAT in the detection of $C$. trachomatis from semen when compared with urine $[41,60]$. Extracting DNA from semen prior to polymerase chain reaction (PCR) or ligase chain reaction (LCR) testing has been shown to greatly improve the detection rate. Thus, if NAAT is to be used for C. trachomatis detection in semen, DNA extraction will likely be essential in a commercial testing system.

The relationship between C. trachomatis antibodies and DNA is still under investigation. Weidner et al. [61] found that there was some (but not all) overlap between men testing positive for Chlamydial antibodies and genetic material, among both seminal and serum samples. Clearly, each fluid and testing method will identify slightly different groups, but the clinical implications of this are unknown. The inconsistent link between Chlamydial antibodies and presence of Chlamydial DNA has been corroborated by other groups $[11,17,28,51]$. It is the authors' opinion after reviewing this literature that the assessment of Chlamydial IgG and IgA antibodies in serum or semen is likely of limited use in the male infertility workup. One benefit of detecting $C$. trachomatis in the infertile male is that it serves as a marker for infection in the female partner. Sperm may serve as vectors for C. trachomatis $[62,63]$, spreading the pathogen to the female reproductive tract [64] and also inducing an immune response to sperm in women [11].

Also noteworthy is the role of seminal leukocytes with Chlamydial infection. It is well known that seminal leukocytes negatively impact male fertility, and studies have demonstrated an association between seminal antibodies to C. trachomatis and seminal inflammation $[23,65,66]$. Bollmann et al. [67] sought to determine if any negative effects are due to the Chlamydia or the leukocytes and found that this was more likely due to the seminal leukocytes and not the presence of $C$. trachomatis.

\section{Male Issues}

The primary site of male Chlamydia infection is the penile urethra [68], with subsequent retrograde infection of the epididymis and testis [69]. The role of Chlamydia infection of the male accessory glands, including the prostate and seminal vesicles, is unclear. Prostatic infection is particularly interesting, as mouse models have demonstrated that Chlamydia may persist in the prostate after treatment, establishing an immune-privileged niche and avoiding the host immune response, which may result in serving as a reservoir for continuous infection [70]. Recent evidence suggests that prostatitis caused by Chlamydia, as opposed to more common pathogens, had lowered sperm concentration, motility, and morphology and that strong correlations between anti-C. trachomatis IgA and sperm concentration and normal forms were noted [71]. Coinfection in these patients may further impair semen parameters.

Chlamydia infection is responsible for $40-80 \%$ of epididymitis [72]. These men can subsequently develop orchitis and prostatitis, which can lead to canalicular system damage, testicular atrophy, and obstructive azoospermia [73, 74]. In addition to the obstructive component, the epididymis plays a crucial role in sperm functional maturation, and $C$. trachomatis infection may negatively impact sperm function [72].

\section{Sperm Parameters}

While a large number of studies have demonstrated that Chlamydia infection has no effect on semen parameters $[6$, $11,17,19,20,23,24,29,32-34,61,75,76]$, both Gdoura and Witkin et al. have identified a relationship between the detection of C. trachomatis DNA in semen and poor sperm motility [11]. There is also some evidence to suggest that infection with C. trachomatis may lead to a defective acrosome reaction [77]. Studies identifying no relationship between Chlamydia infection and poor semen parameters may be difficult to interpret given the unclear relationship between Chlamydial antibodies and current/prior infection. While the data are not conclusive, overall, it seems that the link between Chlamydia infection and sperm parameters is relatively weak. Interestingly though, evidence suggests that Chlamydia infected men will have an improvement in semen parameters [78] and DNA fragmentation rates [74] after treatment with antimicrobials. 


\section{Antibodies}

Any negative effect that Chlamydia actually has on sperm may also be due to the formation of anti-sperm or antiChlamydial antibodies $[12,79,80]$. Detection of antiChlamydial IgA and IgG antibodies in male serum has been associated with poor semen characteristics $[19,35]$ and reduced pregnancy rates regardless of female partner antibody status [30, 58, 81, 82]. In addition, asymptomatic infection with Chlamydia may be the reason for unexplained infertility in some men [72], as infertile men are more likely to be seropositive for antibodies to $C$. trachomatis at a titer of 1:64 or higher, and men with higher titers have a higher probability of being infertile [72].

Finally, the relationship to CHSP60 antibodies is unclear. Antibodies to CHSP60 are known to be related to tubal factor infertility in women, the result of an autoimmune cross-reaction to human HSP60 expressed in the female reproductive tract [83]. In men, Idahl et al. [58] found a decrease in sperm motility but no change in pregnancy rates in men who were CHSP60 IgG positive. Likewise, Karinen et al. found no relationship between CHSP60 IgG expression in men and subfertility [84]. Together these results suggest that the role of CHSP60 in male fertility is quite minimal.

As mentioned the mechanism of any effect is unclear. Is there a direct effect on male fertility or is the effect a result of sexual transmission to the female partner leading to tubal damage?

\section{Cytotoxicity}

While the exact mechanism of Chlamydia induced damage is not known, incubation of sperm with the elementary bodies of $C$. trachomatis leads to decreased sperm motility, stimulates tyrosine phosphorylation [85], and results in cytotoxicity [85]. In addition, the presence of IgA against $C$. trachomatis has been shown to correlate with lipid peroxidation of the sperm membrane [86]. C. trachomatis-induced cell death may also be caused by lipopolysaccharide (as generated by the elementary body), as lipopolysaccharide negating agents have been shown to inhibit the spermatocidal properties of elementary bodies [87]. In addition, it has been shown that lipopolysaccharide can induce sperm to generate reactive oxygen species which may be a component of the toxicity $[88]$.

\section{DNA Fragmentation}

Recent studies have shown that Chlamydia infection may result in sperm DNA fragmentation, which has been associated with a low potential for natural male fecundity [89, 90], reduced fertility potential in vivo and in vitro [91], decreased embryo quality, and lower implantation rates [92]. Satta et al. [93] found that sperm from normospermic men had an increase in DNA fragmentation when incubated with $C$. trachomatis, an effect that occurred quickly and at a low bacterial concentration, suggesting that sperm may become damaged during transit in an infected female genital tract. Likewise, Gallegos et al. [74] found that, in men with
Chlamydia, the mean percentage of sperm with fragmented DNA was $35.2 \%, 3.2$ times higher than in fertile controls (10.8\%). Finally, sperm infected by C. trachomatis may be sufficiently damaged to prevent the successful development of embryos should fertilization be successful [48].

\section{Chlamydia and Pregnancy Outcomes}

Similar to its effect on sperm, the effect of male C. trachomatis on pregnancy rates is not completely clear. Serologic studies have shown mixed results, some studies demonstrating lower pregnancy rates [58], and others demonstrating no difference [33]. Chlamydia can be transmitted by donor insemination [94, 95], likely by direct transmission adherent to sperm [63], and is not always removed by centrifugation prior to insemination or intracytoplasmic sperm injection [96]. Sperm-Chlamydia interaction may be an unrecognized cause of fertilization failure during in vitro fertilization (IVF) [41, 97], and if this is the case, then routine sperm testing prior to advanced reproductive procedures is warranted.

In 1999, Witkin [98] reported that women with cervical anti-Chlamydial and anti-CHSP60 IgA antibodies were three times more likely to have an early pregnancy loss after IVF than women without these antibodies. Further, incubation of embryos in media containing human sera positive for antihuman HSP60 antibodies inhibited embryo development [98]. These results have been corroborated by others [99]. Women without antibodies to CHSP60 have been shown to be five times more likely to have intrauterine conceptions and term deliveries when compared to those with positive serologies [100]. Together, these studies suggest that prior Chlamydial infection has an impact on intrauterine conception and delivery rate, and these outcomes appear to be related to antibodies to CHSP60 or Chlamydial IgG or IgA. This data suggests a role for semen testing in couples undergoing advanced reproductive technologies.

The mechanism for decreased fertility potential in females from prior Chlamydia exposure may be related to the pelvic inflammatory response provoked either by $C$. trachomatis or directly by the organism itself. Interestingly, the human trophoblast has been shown to express the $60 \mathrm{kDa}$ Chlamydial antigen of human heat shock proteins, although this does not normally trigger an immune response [45, 80, 99], and cross-reactivity between heat shock protein previously sensitized to Chlamydia may compromise fetal or maternal cell viability. In addition, the presence of infectious forms of Chlamydia in the spermatozoon nucleus may result in an infected or damaged embryo.

\section{Screening}

One of the conclusions that we drew from our 2012 study [7] is that routing testing for Chlamydia in the infertile male population cannot be recommended given its low prevalence in this population. While recommendations exist for female testing, and indications for testing in fertile men exist (leukocytospermia and symptoms of infection), there are no recommendations that specifically address the indications 
for, and methodology of, Chlamydia testing in infertile men. At this point infertile men are treated in the same manner as fertile men, but should this be the case?

In the United Kingdom, the Royal College of Obstetricians and Gynaecologists Evidence-based Clinical Guidelines [101] recommend that, prior to intrauterine instrumentation, women be offered screening for C. trachomatis. In the United States, the 2012 Institute for Clinical System Improvement recommends Chlamydia screening for all sexually active women of age 25 years and younger, although it makes no recommendations on screening for men. The 2010 American Urological Association Best Practice Statement "The Optimal Evaluation of the Infertile Male" states that "those patients with true leukocytospermia $\left(>1 \times 10^{6} / \mathrm{mL}\right)$ be evaluated for a genital tract infection or inflammation" but there are no specific recommendations on the sample type or testing methodology. Although screening for C. trachomatis among infertile men is practiced widely, it is not addressed in the Male Infertility Best Practice Guidelines published by the American Society for Reproductive Medicine and the American Urological Association [102].

At our center we found a rate of C. trachomatis of $0.304 \%$ in asymptomatic Canadian infertile men, significantly lower than that of the general population [7]. If cost is analyzed, we found that the reagent cost alone to diagnose one case of Chlamydia was $\$ 38,669$, not inconsequential [7]. Given that the direct fertility consequences of Chlamydia infection in males are not completely clear, the utility of Chlamydia screening in this low-risk population may have little benefit apart from preventing infection to the female partner. In this respect, it may serve as a form of secondary disease prevention employed by some infertility centers, as it may reduce health care cost by decreasing long-term reproductive complications [65]. However, as noted above, the rates of $C$. trachomatis infection are regionally variable, and screening should correlate with local prevalence rates.

Finally, there are no studies demonstrating the effectiveness of screening for asymptomatic C. trachomatis in men with infertility for either reducing transmission of Chlamydia to female partners or preventing infections or complications in males $[103,104]$. Large population-based studies in women have demonstrated reductions in PID with increased Chlamydia screening efforts [105]. However, other Chlamydia screening studies have not demonstrated a reduction in adverse female reproductive outcomes or epididymitis [106]. In men, the literature focuses on riskgroup (primarily age directed) screening [107-109], as it has been shown to be cost-effective in these populations. In one proposed algorithm, if the female partner has a history of ectopic pregnancy, testing for anti-CHSP60 antibodies could be performed. Those with positive antibodies may be counseled to consider immediate IVF to optimize their chance for a live birth [73].

\section{Conclusions}

Our prior research has shown that the prevalence of Chlamydia in our infertile male population is low (0.304\%), although regional prevalence is variable. The reasons for this are likely multifactorial, related to actual differences in infection rates, testing methodology, and bodily fluid tested. While the impact of C. trachomatis infection on female fertility is well established, its role in male infertility is less clear. In all probability, a direct connection between disturbed male fertility, impaired function of the male accessory glands, and C. trachomatis infection only exists in isolated cases. Furthermore, the low detection rate in infertile men of about $0.3 \%$ means that at best only a small proportion of cases of male infertility are due to $C$. trachomatis infection. The optimal testing method for Chlamydia is unclear at this point; infections will be missed if urine is the only test specimen and semen is not tested as well. A validated, commercially available testing system for semen needs to be developed so that a standardized methodology can be recommended for universal use.

\section{Conflict of Interests}

The authors declare that there is no conflict of interests regarding the publication of this paper.

\section{References}

[1] R. C. Brunham and M. L. Rekart, "Considerations on Chlamydia trachomatis disease expression," FEMS Immunology \& Medical Microbiology, vol. 55, no. 2, pp. 162-166, 2009.

[2] K. Purvis and E. Christiansen, "Infection in the male reproductive tract. Impact, diagnosis and treatment in relation to male infertility," International Journal of Andrology, vol. 16, no. 1, pp. 1-13, 1993.

[3] W. J. Hellstrom, J. Schachter, R. L. Sweet, and R. D. McClure, "Is there a role for Chlamydia trachomatis and genital mycoplasma in male infertility?" Fertility and Sterility, vol. 48, no. 2, pp. 337339, 1987.

[4] A. Agarwal, I. Ikemoto, and K. R. Loughlin, "Relationship of sperm parameters with levels of reactive oxygen species in semen specimens," Journal of Urology, vol. 152, no. 1, pp. 107110, 1994.

[5] F.-M. Kohn, I. Erdmann, T. Oeda, K. F. El Mulla, H. G. Schiefer, and W.-B. Schill, "Influence of urogenital infections on sperm functions," Andrologia, vol. 30, supplement 1, pp. 73-80, 1998.

[6] P. Vigil, P. Morales, A. Tapia, R. Riquelme, and A. M. Salgado, "Chlamydia trachomatis infection in male partners of infertile couples: incidence and sperm function," Andrologia, vol. 34, no. 3, pp. 155-161, 2002.

[7] T. Domes, K. C. Lo, E. D. Grober, J. B. Mullen, T. Mazzulli, and K. Jarvi, "The utility and cost of Chlamydia trachomatis and Neisseria gonorrhoeae screening of a male infertility population," Fertility and Sterility, vol. 97, no. 2, pp. 299-305, 2012.

[8] R. C. Brunham and J. Rey-Ladino, "Immunology of Chlamydia infection: implications for a Chlamydia trachomatis vaccine," Nature Reviews Immunology, vol. 5, no. 2, pp. 149-161, 2005.

[9] K. A. Cunningham and K. W. Beagley, "Male genital tract chlamydial infection: implications for pathology and infertility," Biology of Reproduction, vol. 79, no. 2, pp. 180-189, 2008.

[10] B. Nagy, G. Corradi, Z. Vajda, R. Gimes, and S. Csomor, "The occurrence of Chlamydia trachomatis in the semen of men 
participating in an IVF programme," Human Reproduction, vol. 4, no. 1, pp. 54-56, 1989.

[11] S. S. Witkin, J. Jeremias, J. A. Grifo, and W. J. Ledger, "Detection of Chlamydia trachomatis in semen by the polymerase chain reaction in male members of infertile couples," American Journal of Obstetrics and Gynecology, vol. 168, no. 5, pp. 14571462, 1993.

[12] M. G. Munoz and S. S. Witkin, "Autoimmunity to spermatozoa, asymptomatic Chlamydia trachomatis genital tract infection and $\gamma \delta$ T lymphocytes in seminal fluid from the male partners of couples with unexplained infertility," Human Reproduction, vol. 10, no. 5, pp. 1070-1074, 1995.

[13] J. Suominen, M. Gronroos, P. Terho, and L. Wichmann, "Chronic prostatitis, Chlamydia trachomatis and infertility," International Journal of Andrology, vol. 6, no. 5, pp. 405-413, 1983.

[14] S. Bjercke and K. Purvis, "Chlamydial serology in the investigation of infertility," Human Reproduction, vol. 7, no. 5, pp. 621624, 1992.

[15] W. Eggert-Kruse, S. Pohl, H. Naher, W. Tilgen, and B. Runnebaum, "Microbial colonization and sperm-mucus interaction: results in 1000 infertile couples," Human Reproduction, vol. 7, no. 5, pp. 612-620, 1992.

[16] Z. Samra, Y. Soffer, and M. Pansky, "Prevalence of genital chlamydia and mycoplasma infection in couples attending a male infertility clinic," European Journal of Epidemiology, vol. 10, no. 1, pp. 69-73, 1994.

[17] S. Dieterle, J. B. Mahony, K. E. Luinstra, and W. Stibbe, "Chlamydial immunoglobulin IgG and IgA antibodies in serum and semen are not associated with the presence of Chlamydia trachomatis DNA or rRNA in semen from male partners of infertile couples," Human Reproduction, vol. 10, no. 2, pp. 315319, 1995.

[18] W. Eggert-Kruse, N. Buhlinger-Gopfarth, G. Rohr et al., "Antibodies to Chlamydia trachomatis in semen and relationship with parameters of male fertility," Human Reproduction, vol. 11, no. 7, pp. 1408-1417, 1996.

[19] T. Cengiz, L. Aydoganli, M. Baykam et al., "Chlamydial infections and male infertility," International Urology and Nephrology, vol. 29, no. 6, pp. 687-693, 1997.

[20] W. Eggert-Kruse, G. Rohr, T. Demirakca et al., "Chlamydial serology in 1303 asymptomatic subfertile couples," Human Reproduction, vol. 12, no. 7, pp. 1464-1475, 1997.

[21] M. S. Bornman, T. N. Ramuthaga, M. F. Mahomed, A. S. Greeff, H. H. Crewe-Brown, and S. Reif, "Chlamydial infection in asymptomatic infertile men attending an andrology clinic," Archives of Andrology, vol. 41, no. 3, pp. 203-208, 1998.

[22] R. Levy, M.-P. Layani-Milon, S. Giscard D'Estaing et al., "Screening for Chlamydia trachomatis and Ureaplasma urealyticum infection in semen from asymptomatic male partners of infertile couples prior to in vitro fertilisation," International Journal of Andrology, vol. 22, no. 2, pp. 113-118, 1999.

[23] F. R. Ochsendorf, K. Özdemir, H. Rabenau et al., "Chlamydia trachomatis and male infertility: chlamydia-IgA antibodies in seminal plasma are C. trachomatis specific and associated with an inflammatory response," Journal of the European Academy of Dermatology and Venereology, vol. 12, no. 2, pp. 143-152, 1999.

[24] B. Habermann and W. Krause, "Altered sperm function or sperm antibodies are not associated with chlamydial antibodies in infertile men with leucocytospermia," Journal of the European Academy of Dermatology and Venereology, vol. 12, no. 1, pp. 2529, 1999.
[25] S. Penna Videau, J. Cermeno Vivas, and N. Salazar, "IgA antibodies to Chlamydia trachomatis and seminal parameters in asymptomatic infertile males," Archives of Andrology, vol. 46, no. 3, pp. 189-195, 2001.

[26] J. Mania-Pramanik, J. Gokral, and P. K. Meherji, “Chlamydia trachomatis infection among asymptomatic males in an infertility clinic," Indian Journal of Dermatology, Venereology and Leprology, vol. 67, no. 5, pp. 242-245, 2001.

[27] R. Bollmann, S. Engel, R. Petzoldt, and U. B. Göbel, “Chlamydia trachomatis in andrologic patients-direct and indirect detection," Infection, vol. 29, no. 3, pp. 113-118, 2001.

[28] R. Gdoura, F. Daoudi, F. Bouzid et al., "Detection of Chlamydia trachomatis in semen and urethral specimens from male members of infertile couples in Tunisia," European Journal of Contraception and Reproductive Health Care, vol. 6, no. 1, pp. 14-20, 2001.

[29] W. Eggert-Kruse, G. Rohr, B. Kunt et al., "Prevalence of Chlamydia trachomatis in subfertile couples," Fertility and Sterility, vol. 80, no. 3, pp. 660-663, 2003.

[30] A. Idahl, J. Boman, U. Kumlin, and J. I. Olofsson, "Demonstration of Chlamydia trachomatis IgG antibodies in the male partner of the infertile couple is correlated with a reduced likelihood of achieving pregnancy," Human Reproduction, vol. 19, no. 5, pp. 1121-1126, 2004.

[31] F. Hamdad-Daoudi, J. Petit, and F. Eb, "Assessment of Chlamydia trachomatis infection in asymptomatic male partners of infertile couples," Journal of Medical Microbiology, vol. 53, part 10, pp. 985-990, 2004.

[32] S. Hosseinzadeh, A. Eley, and A. A. Pacey, "Semen quality of men with asymptomatic chlamydial infection," Journal of Andrology, vol. 25, no. 1, pp. 104-109, 2004.

[33] B. de Barbeyrac, A. Papaxanthos-Roche, C. Mathieu et al., "Chlamydia trachomatis in subfertile couples undergoing an in vitro fertilization program: a prospective study," European Journal of Obstetrics Gynecology and Reproductive Biology, vol. 129, no. 1, pp. 46-53, 2006.

[34] R. Gdoura, W. Kchaou, L. Ammar-Keskes et al., "Assessment of Chlamydia trachomatis, Ureaplasma urealyticum, Ureaplasma parvum, Mycoplasma hominis, and Mycoplasma genitalium in semen and first void urine specimens of asymptomatic male partners of infertile couples," Journal of Andrology, vol. 29, no. 2, pp. 198-206, 2008.

[35] P. Joki-Korpela, N. Sahrakorpi, M. Halttunen, H. Surcel, J. Paavonen, and A. Tiitinen, "The role of Chlamydia trachomatis infection in male infertility," Fertility and Sterility, vol. 91, supplement 4, pp. 1448-1450, 2009.

[36] V. Ouzounova-Raykova, I. Ouzounova, and I. Mitov, "Chlamydia trachomatis infection as a problem among male partners of infertile couples," Andrologia, vol. 41, no. 1, pp. 14-19, 2009.

[37] A. Kokab, M. M. Akhondi, M. R. Sadeghi et al., "Raised inflammatory markers in semen from men with asymptomatic chlamydial infection," Journal of Andrology, vol. 31, no. 2, pp. 114-120, 2010.

[38] W. Eggert-Kruse, M. Weltin, and T. Strowitzki, "Are chlamydial lipopolysaccachide-directed antibodies in seminal plasma or serum clinically significant during investigation of male infertility?" Urology, vol. 77, no. 5, pp. 1101-1106, 2011.

[39] R. Rybar, P. Prinosilova, V. Kopecka et al., "The effect of bacterial contamination of semen on sperm chromatin integrity and standard semen parameters in men from infertile couples," Andrologia, vol. 44, supplement 1, pp. 410-418, 2012. 
[40] S. D. Datta, E. Torrone, D. Kruszon-Moran et al., "Chlamydia trachomatis trends in the united states among persons 14 to 39 Years of Age, 1999-2008," Sexually Transmitted Diseases, vol. 39, no. 2, pp. 92-96, 2012.

[41] A. Eley and A. A. Pacey, "The value of testing semen for Chlamydia trachomatis in men of infertile couples," International Journal of Andrology, vol. 34, no. 5, pp. 391-401, 2011.

[42] K. Senior, "Chlamydia: a much underestimated STI," The Lancet Infectious Diseases, vol. 12, no. 7, pp. 517-518, 2012.

[43] H. Öhman, A. Tiitinen, M. Halttunen, M. Lehtinen, J. Paavonen, and H.-M. Surcel, "Cytokine polymorphisms and severity of tubal damage in women with chlamydia-associated infertility," Journal of Infectious Diseases, vol. 199, no. 9, pp. 1353-1359, 2009.

[44] S. L. Gottlieb, D. H. Martin, F. Xu, G. I. Byrne, and R. C. Brunham, "Summary: the natural history and immunobiology of Chlamydia trachomatis genital infection and implications for chlamydia control," Journal of Infectious Diseases, vol. 201, supplement 2, pp. S190-S204, 2010.

[45] I. M. Linhares and S. S. Witkin, "Immunopathogenic consequences of Chlamydia trachomatis $60 \mathrm{kDa}$ heat shock protein expression in the female reproductive tract," Cell Stress and Chaperones, vol. 15, no. 5, pp. 467-473, 2010.

[46] A. Hjelholt, G. Christiansen, T. G. Johannesson, H. J. Ingerslev, and S. Birkelund, "Tubal factor infertility is associated with antibodies against Chlamydia trachomatis heat shock protein 60 (HSP60) but not human HSP60," Human Reproduction, vol. 26, no. 8, pp. 2069-2076, 2011.

[47] M. Chernesky, S. Castriciano, J. Sellors et al., "Detection of Chlamydia trachomatis antigens in urine as an alternative to swabs and cultures," Journal of Infectious Diseases, vol. 161, no. 1, pp. 124-126, 1990.

[48] A. Eley, S. Hosseinzadeh, H. Hakimi, I. Geary, and A. A. Pacey, "Apoptosis of ejaculated human sperm is induced by co-incubation with Chlamydia trachomatis lipopolysaccharide," Human Reproduction, vol. 20, no. 9, pp. 2601-2607, 2005.

[49] R. Peeling and J. Embree, "Screening for sexually transmitted infection pathogens in semen samples," The Canadian Journal of Infectious Diseases \& Medical Microbiology, vol. 16, no. 2, pp. 73-76, 2005.

[50] G. Gallegos-Avila, M. Ortega-Martínez, B. Ramos-González, R. Tijerina-Menchaca, J. Ancer-Rodríguez, and G. JaramilloRangel, "Ultrastructural findings in semen samples of infertile men infected with Chlamydia trachomatis and mycoplasmas," Fertility and Sterility, vol. 91, no. 3, pp. 915-919, 2009.

[51] H. Wolff, U. Neubert, M. Volkenandt et al., "Detection of Chlamydia trachomatis in semen by antibody-enzyme immunoassay compared with polymerase chain reaction, antigen-enzyme immunoassay, and urethral cell culture," Fertility and Sterility, vol. 62, no. 6, pp. 1250-1254, 1994.

[52] A. Eley, "How to detect Chlamydia trachomatis in males?" Journal of Andrology, vol. 32, no. 1, pp. 15-22, 2011.

[53] D. Taylor-Robinson and B. J. Thomas, "Laboratory techniques for the diagnosis of chlamydial infections," Genitourinary Medicine, vol. 67, no. 3, pp. 256-266, 1991.

[54] K. H. Tjiam, B. Y. van Heijst, A. A. Polak-Vogelzang et al., "Sexually communicable micro-organisms in human semen samples to be used for artificial insemination by donor," Genitourinary Medicine, vol. 63, no. 2, pp. 116-118, 1987.

[55] M. Puolakkainen, E. Vesterinen, E. Purola, P. Saikku, and J. Paavonen, "Persistence of chlamydial antibodies after pelvic inflammatory disease," Journal of Clinical Microbiology, vol. 23, no. 5, pp. 924-928, 1986.
[56] A. K. Rodgers, J. Wang, Y. Zhang et al., "Association of tubal factor infertility with elevated antibodies to Chlamydia trachomatis caseinolytic protease P," American Journal of Obstetrics \& Gynecology, vol. 203, no. 5, pp. 494.e7-494.e14, 2010.

[57] C. Campanella, A. Marino Gammazza, L. Mularoni, F. Cappello, G. Zummo, and V. Di Felice, "A comparative analysis of the products of GROEL-1 gene from Chlamydia trachomatis serovar D and the HSP60 varl transcript from Homo sapiens suggests a possible autoimmune response," International Journal of Immunogenetics, vol. 36, no. 1, pp. 73-78, 2009.

[58] A. Idahl, L. Abramsson, U. Kumlin, J. A. Liljeqvist, and J. I. Olofsson, "Male serum Chlamydia trachomatis IgA and IgG, but not heat shock protein $60 \mathrm{IgG}$, correlates with negatively affected semen characteristics and lower pregnancy rates in the infertile couple," International Journal of Andrology, vol. 30, no. 2, pp. 99-107, 2007.

[59] J. Schachter, W. E. Stamm, and T. C. Quinn, "Discrepant analysis and screening for Chlamydia trachomatis," The Lancet, vol. 348, no. 9037, pp. 1308-1309, 1996.

[60] Y. Pannekoek, S. M. Westenberg, P. P. Eijk et al., "Assessment of Chlamydia trachomatis infection of semen specimens by ligase chain reaction," Journal of Medical Microbiology, vol. 52, part 9, pp. 777-779, 2003.

[61] W. Weidner, E. Floren, O. Zimmermann, D. Thiele, and M. Ludwig, "Chlamydial antibodies in semen: search for, "silent" chlamydial infections in asymptomatic andrological patients," Infection, vol. 24, no. 4, pp. 309-313, 1996.

[62] T. Erbengi, "Ultrastructural observations on the entry of Chlamydia trachomatis into human spermatozoa," Human Reproduction, vol. 8, no. 3, pp. 416-421, 1993.

[63] P. Wolner-Hanssen and P.-A. Mardh, "In vitro tests of the adherence of Chlamydia trachomatis to human spermatozoa," Fertility and Sterility, vol. 42, no. 1, pp. 102-107, 1984.

[64] J. Friberg, E. Confino, M. Suarez, and N. Gleicher, "Chlamydia trachomatis attached to spermatozoa recovered from the peritoneal cavity of patients with salpingitis," Journal of Reproductive Medicine for the Obstetrician and Gynecologist, vol. 32, no. 2, pp. 120-122, 1987.

[65] J. Paavonen and W. Eggert-Kruse, "Chlamydia trachomatis: impact on human reproduction," Human Reproduction Update, vol. 5, no. 5, pp. 433-447, 1999.

[66] H. Wolff, U. Neubert, M. Zebhauser, G. Bezold, H. C. Korting, and M. Meurer, "Chlamydia trachomatis induces an inflammatory response in the male genital tract and is associated with altered semen quality," Fertility and Sterility, vol. 55, no. 5, pp. 1017-1019, 1991.

[67] R. Bollmann, S. Engel, D. Sagert, and U. B. Gobel, "Investigations on the detection of Chlamydia trachomatis infections in infertile male outpatients," Andrologia, vol. 30, supplement 1, pp. 23-27, 1998.

[68] F. M. Mulcahy, C. J. Bignell, R. Rajakumar et al., "Prevalence of chlamydial infection in acute epididymo-orchitis," Genitourinary Medicine, vol. 63, no. 1, pp. 16-18, 1987.

[69] T. H. Trojian, T. S. Lishnak, and D. Heiman, "Epididymitis and orchitis: an overview," American Family Physician, vol. 79, no. 7, pp. 583-587, 2009.

[70] J. P. MacKern-Oberti, R. D. Motrich, M. L. Breser et al., "Male rodent genital tract infection with chlamydia muridarum: persistence in the prostate gland that triggers self-immune reactions in genetically susceptible hosts," Journal of Urology, vol. 186, no. 3, pp. 1100-1106, 2011. 
[71] S. Mazzoli, T. Cai, P. Addonisio, A. Bechi, N. Mondaini, and R. Bartoletti, "Chlamydia trachomatis infection is related to poor semen quality in young prostatitis patients," European Urology, vol. 57, no. 4, pp. 708-714, 2010.

[72] G. A. Greendale, S. T. Haas, K. Holbrook, B. Walsh, J. Schachter, and R. S. Phillips, "The relationship of Chlamydia trachomatis infection and male infertility," American Journal of Public Health, vol. 83, no. 7, pp. 996-1001, 1993.

[73] A. J. Stephens, M. Aubuchon, and D. J. Schust, "Antichlamydial antibodies, human fertility, and pregnancy wastage," Infectious Diseases in Obstetrics and Gynecology, vol. 2011, Article ID 525182, 9 pages, 2011.

[74] G. Gallegos, B. Ramos, R. Santiso, V. Goyanes, J. Gosálvez, and J. L. Fernández, "Sperm DNA fragmentation in infertile men with genitourinary infection by Chlamydia trachomatis and Mycoplasma," Fertility and Sterility, vol. 90, no. 2, pp. 328$334,2008$.

[75] I. Günyeli, F. Abike, I. Dünder et al., "Chlamydia, Mycoplasma and Ureaplasma infections in infertile couples and effects of these infections on fertility," Archives of Gynecology and Obstetrics, vol. 283, no. 2, pp. 379-385, 2011.

[76] R. D. Motrich, C. Cuffini, J. P. Mackern Oberti, M. Maccioni, and V. E. Rivero, "Chlamydia trachomatis occurrence and its impact on sperm quality in chronic prostatitis patients," Journal of Infection, vol. 53, no. 3, pp. 175-183, 2006.

[77] A. Jungwirth, A. Straberger, B. Esterbauer, K. Fink, and N. Schmeller, "Acrosome reaction in Chlamydia-positive and negative patients," Andrologia, vol. 35, no. 5, pp. 314-316, 2003.

[78] G. M. Custo, V. Lauro, C. Saitto, and R. F. Frongillo, "Chlamydial infection and male infertility: an epidemiological study," Archives of Andrology, vol. 23, no. 3, pp. 243-248, 1989.

[79] S. S. Witkin, I. Kligman, and A. M. Bongiovanni, "Relationship between an asymptomatic male genital tract exposure to Chlamydia trachomatis and an autoimmune response to spermatozoa," Human Reproduction, vol. 10, no. 11, pp. 29522955, 1995.

[80] S. S. Witkin, K. M. Sultan, G. S. Neal, J. Jeremias, J. A. Grifo, and Z. Rosenwaks, "Unsuspected Chlamydia trachomatis infection and in vitro fertilization outcome," American Journal of Obstetrics and Gynecology, vol. 171, no. 5, pp. 1208-1214, 1994.

[81] W. Eggert-Kruse, I. Gerhard, H. Naher, W. Tilgen, and B. Runnebaum, "Chlamydial infection-a female and/or male infertility factor?” Fertility and Sterility, vol. 53, no. 6, pp. 10371043, 1990.

[82] L. Karinen, A. Pouta, A.-L. Hartikainen et al., "Association between Chlamydia trachomatis antibodies and subfertility in the Northern Finland Birth Cohort 1966 (NFBC 1966), at the age of 31 years," Epidemiology and Infection, vol. 132, no. 5, pp. 977-984, 2004.

[83] A. Neuer, S. D. Spandorfer, P. Giraldo, S. Dieterle, Z. Rosenwaks, and S. S. Witkin, "The role of heat shock proteins in reproduction," Human Reproduction Update, vol. 6, no. 2, pp. 149-159, 2000.

[84] L. Karinen, A. Pouta, A.-L. Hartikainen et al., "Antibodies to Chlamydia trachomatis heat shock proteins Hsp60 and Hsp10 and subfertility in general population at age 31," American Journal of Reproductive Immunology, vol. 52, no. 5, pp. 291-297, 2004.

[85] S. Hosseinzadeh, I. A. Brewis, A. Eley, and A. A. Pacey, "Co-incubation of human spermatozoa with Chlamydia trachomatis serovar E causes premature sperm death," Human Reproduction, vol. 16, no. 2, pp. 293-299, 2001.
[86] A. Segnini, M. I. Camejo, and F. Proverbio, "Chlamydia trachomatis and sperm lipid peroxidation in infertile men," Asian Journal of Andrology, vol. 5, no. 1, pp. 47-49, 2003.

[87] S. Hosseinzadeh, A. A. Pacey, and A. Eley, "Chlamydia trachomatis-induced death of human spermatozoa is caused primarily by lipopolysaccharide," Journal of Medical Microbiology, vol. 52, no. 3, pp. 193-200, 2003.

[88] K. Urata, H. Narahara, Y. Tanaka, T. Egashira, F. Takayama, and I. Miyakawa, "Effect of endotoxin-induced reactive oxygen species on sperm motility," Fertility and Sterility, vol. 76, no. 1, pp. 163-166, 2001.

[89] D. P. Evenson, L. K. Jost, D. Marshall et al., "Utility of the sperm chromatin structure assay as a diagnostic and prognostic tool in the human fertility clinic," Human Reproduction, vol. 14, no. 4, pp. 1039-1049, 1999.

[90] M. Spano, J. P. Bonde, H. I. Hjollund, H. A. Kolstad, E. Cordelli, and G. Leter, "Sperm chromatin damage impairs human fertility. The Danish First Pregnancy Planner Study Team," Fertility and Sterility, vol. 73, no. 1, pp. 43-50, 2000.

[91] A. Zini, K. Kamal, D. Phang, J. Willis, and K. Jarvi, "Biologic variability of sperm DNA denaturation in infertile men," Urology, vol. 58, no. 2, pp. 258-261, 2001.

[92] R. Angelopoulou, K. Plastira, and P. Msaouel, "Spermatozoal sensitive biomarkers to defective protaminosis and fragmented DNA," Reproductive Biology and Endocrinology, vol. 5, p. 36, 2007.

[93] A. Satta, A. Stivala, A. Garozzo et al., "Experimental Chlamydia trachomatis infection causes apoptosis in human sperm," Human Reproduction, vol. 21, no. 1, pp. 134-137, 2006.

[94] T. C. Nagel, G. E. Tagatz, and B. F. Campbell, “Transmission of Chlamydia trachomatis by artificial insemination," Fertility and Sterility, vol. 46, no. 5, pp. 959-960, 1986.

[95] A. J. C. van den Brule, D. J. Hemrika, J. M. M. Walboomers et al., "Detection of Chlamydia trachomatis in semen of artificial insemination donors by the polymerase chain reaction," Fertility and Sterility, vol. 59, no. 5, pp. 1098-1104, 1993.

[96] N. Al-Mously, N. A. Cross, A. Eley, and A. A. Pacey, "Real-time polymerase chain reaction shows that density centrifugation does not always remove Chlamydia trachomatis from human semen," Fertility and Sterility, vol. 92, no. 5, pp. 1606-1615, 2009.

[97] A. A. Pacey and A. Eley, "Chlamydia trachomatis and male fertility," Human Fertility, vol. 7, no. 4, pp. 271-276, 2004.

[98] S. S. Witkin, "Immunity to heat shock proteins and pregnancy outcome," Infectious Diseases in Obstetrics and Gynecology, vol. 7, no. 1-2, pp. 35-38, 1999.

[99] S. Jakus, A. Neuer, S. Dieterle, A. M. Bongiovanni, and S. S. Witkin, "Antibody to the Chlamydia trachomatis $60 \mathrm{kDa}$ heat shock protein in follicular fluid and in vitro fertilization outcome," American Journal of Reproductive Immunology, vol. 59, no. 2, pp. 85-89, 2008.

[100] I. Sziller, P. Fedorcsák, Z. Csapó et al., "Circulating antibodies to a conserved epitope of the Chlamydia trachomatis $60-\mathrm{kDa}$ heat shock protein is associated with decreased spontaneous fertility rate in ectopic pregnant women treated by salpingectomy," American Journal of Reproductive Immunology, vol. 59, no. 2, pp. 99-104, 2008.

[101] Royal College of Obstetricians and Gynaecologists Evidencebased Clinical Guidelines, "Guideline Summary No. 3: the management of infertility in secondary care," BJU International, vol. 83, no. 6, pp. 641-645, 1999. 
[102] Male Infertility Best Practice Policy Committee of the American Urological Association and Practice Committee of the American Society for Reproductive Medicine, "Report on optimal evaluation of the infertile male," Fertility and Sterility, vol. 86, supplement 1, no. 5, pp. S202-S209, 2006.

[103] H. D. Nelson and M. Helfand, "Screening for chlamydial infection," American Journal of Preventive Medicine, vol. 20, supplement 3, pp. 95-107, 2001.

[104] D. S. Meyers, H. Halvorson, and S. Luckhaupt, "Screening for chlamydial infection: an evidence update for the U.S. Preventive Services Task Force," Annals of Internal Medicine, vol. 147, no. 2, pp. 135-142, 2007.

[105] K. Owusu-Edusei Jr., M. K. Bohm, H. W. Chesson, and C. K. Kent, "Chlamydia screening and pelvic inflammatory disease. Insights from exploratory time-series analyses," American Journal of Preventive Medicine, vol. 38, no. 6, pp. 652-657, 2010.

[106] B. Andersen, I. Van Valkengoed, I. Sokolowski, J. K. Møller, L. Østergaard, and F. Olesen, "Impact of intensified testing for urogenital Chlamydia trachomatis infections: a randomised study with 9-year follow-up," Sexually Transmitted Infections, vol. 87, no. 2, pp. 156-161, 2011.

[107] D. R. Blake, N. Maldeis, M. R. Barnes, A. Hardick, T. C. Quinn, and C. A. Gaydos, "Cost-effectiveness of screening strategies for Chlamydia trachomatis using cervical swabs, urine, and selfobtained vaginal swabs in a sexually transmitted disease clinic setting," Sexually Transmitted Diseases, vol. 35, no. 7, pp. 649655, 2008.

[108] B. Andersen, P. O. Eidner, D. Hagensen, S. Lomborg, and G. Hoff, "Opportunities screening of young men for urogenital Chlamydia trachomatis infection in general practice," Scandinavian Journal of Infectious Diseases, vol. 37, no. 1, pp. 35-39, 2005.

[109] R. L. Nevin, E. E. Shuping, K. D. Frick, J. C. Gaydos, and C. A. Gaydos, "Cost and effectiveness of chlamydia screening among male military recruits: Markov modeling of complications averted through notification of prior female partners," Sexually Transmitted Diseases, vol. 35, no. 8, pp. 705-713, 2008. 


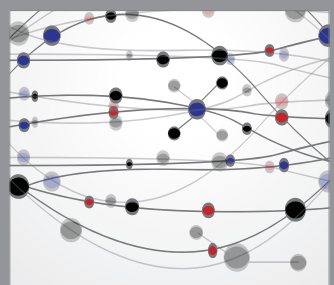

The Scientific World Journal
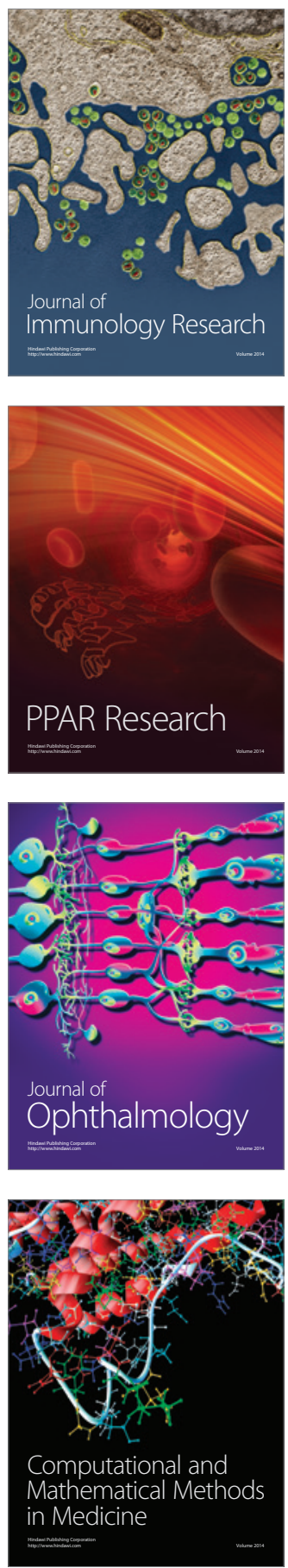

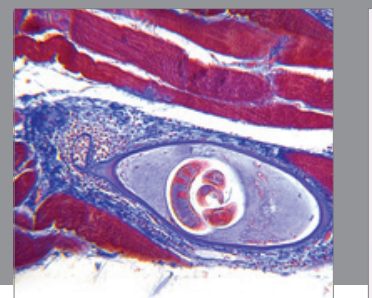

Gastroenterology

Research and Practice
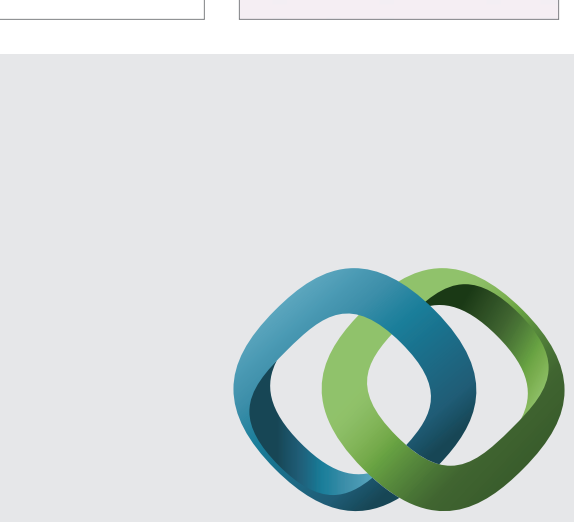

\section{Hindawi}

Submit your manuscripts at

http://www.hindawi.com
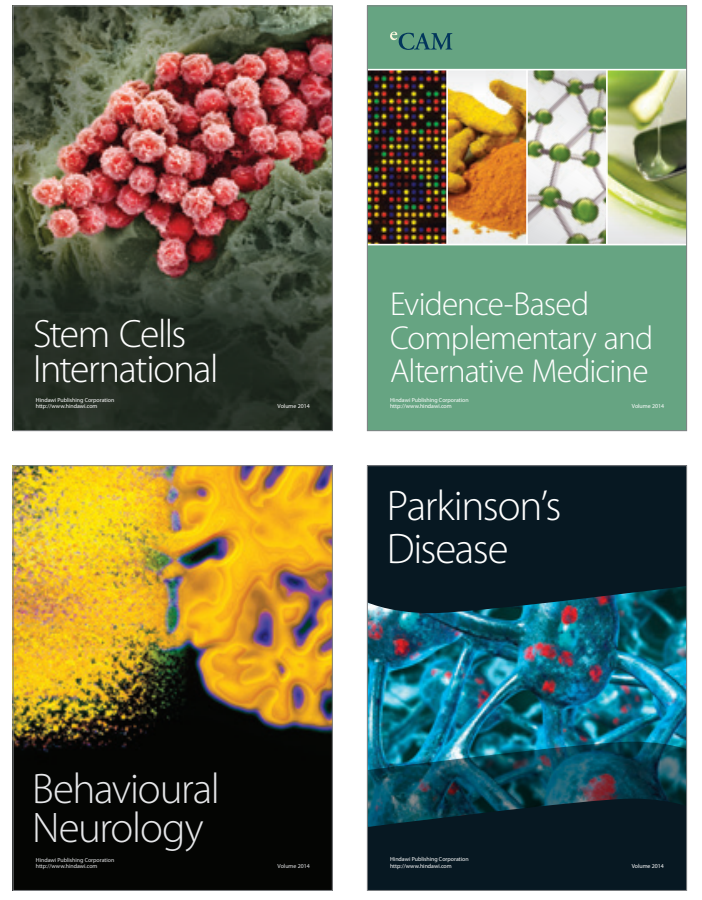
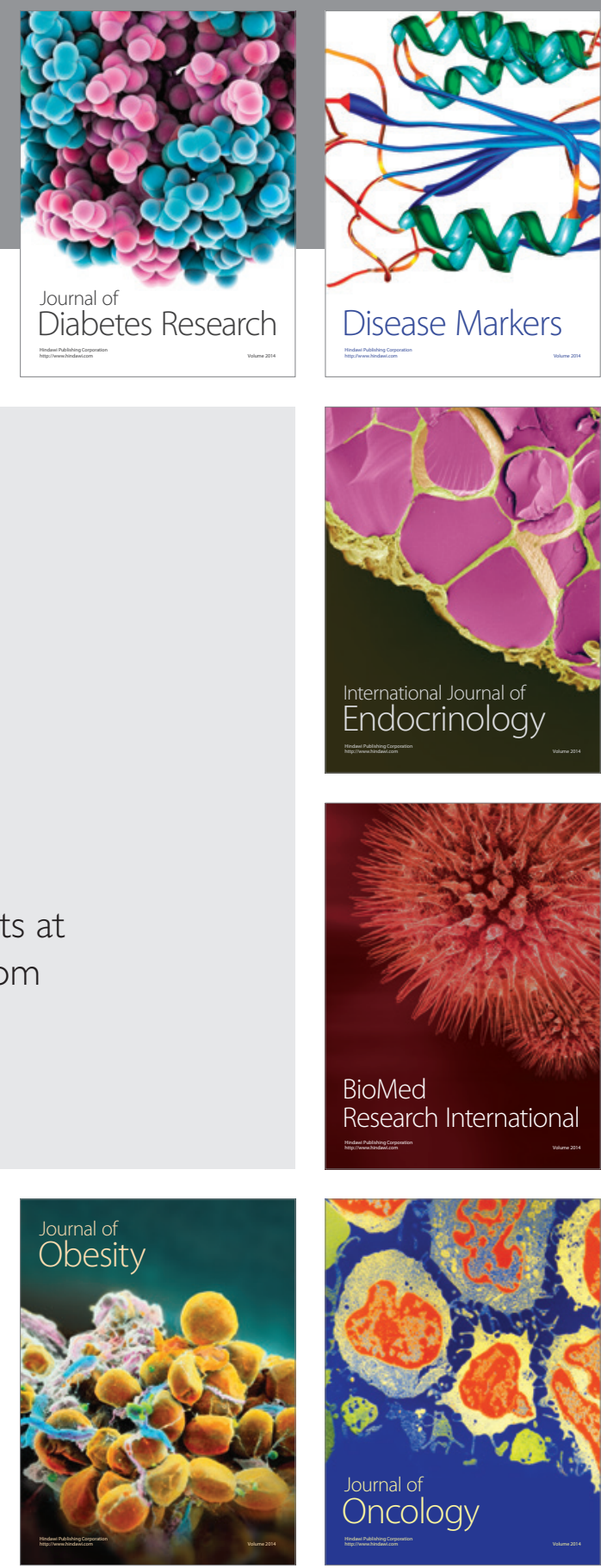

Disease Markers
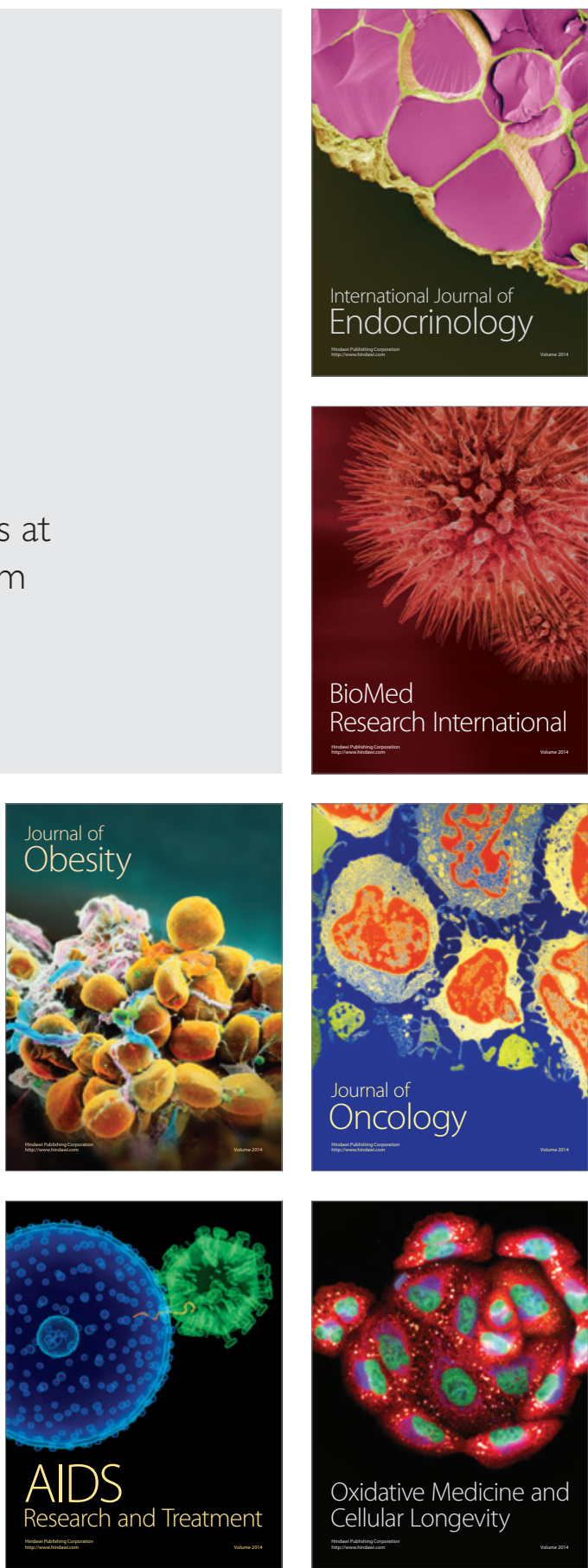